\title{
Reseña de Sentencias del Tribunal Constitucional que aparecen publicadas en el BOE durante el tercer trimestre de 1991
}

\author{
Francisco Javier Fernández González \\ Seminario de Derecho Administrativo \\ Universidad de Oviedo
}

B.O.E. DE 8 DE JULIO DE 1.991. SUPLEMENTO DEL No 162

\section{SENT. N' 119/1991, DE 3 DE JUNIO. SALA SEGUNDA. RECURSO DE AMPARO No $1676 / 1988$. ALVARO RODRIGUEZ BEREIJO.}

OBJETO: Promovido por la Entidad mercantil «Radio Costablanca n. ${ }^{\circ}$ 1, Europea, Sociedad Anónima», contra las resoluciones del Director del Gabinete del Presidente de la Generalidad Valenciana y de la Directora General de Medios de Comunicación Social, de la misma Comunidad Autónoma, de 10 y 16 de julio de 1987, respectivamente, que acordaron la interrupción de las emisiones de Radio Costablanca-Benacantil (Alicante) y el precintado de los equipos necesarios para realizarlas por carecer aquélla de la preceptiva concesión administrativa; así como contra las Sentencias de 14 de enero y 3 de octubre de 1988, de la Sala de lo Contencioso-Administrativo de la Audiencia Territorial de Valencia y de la Sala Quinta del Tribunal Supremo, que confirmaron dichas Resoluciones. Entiende la demandante de amparo que las Resoluciones y Sentencias impugnadas son lesivas de los derechos fundamentales y libertades públicas reconocidos en los artículos 20.1.a) y d), 24.1 y 25.1 de la Constitución.

MATERIAS: Pretendida lesión del derecho a la tutela judicial efectiva por no plantear el órgano judicial la cuestión de inconstitucionalidad (art. 24.1 CE).

- El TC ha reiterado que si bien las partes pueden instar del órgano judicial el planteamiento de la cuestión de inconstitucionalidad, la decisión de suscitarla es prerrogativa exclusiva e irrevisable del órgano judicial.

Pretendida lesión del principio de legalidad de las sanciones administrativas (art. 25.1 CE).

- La demandante aduce que la Administración demandada no ha invocado norma material alguna que pudiera justificar la orden de clausura, porque dicha normativa era en aquel momento inexistente. 
- Pero la base normativa para tal acto se encuentra en los apartados 1 y 2 del art. 3 del RD 1433/1979, de 8 de junio, por el que se establece el Plan Técnico Transitorio del Servicio Público de Radiodifusión Sonora en ondas métricas con modulación de frecuencia.

- Además, no puede reconocerse que la medida adoptada en este caso tuviera, en rigor, carácter de sanción. Carácter que sería predicable de aquélla medida si hubiera obedecido al incumplimiento de las obligaciones derivadas de la relación jurídica originada por la concesión administrativa para emitir, concesión, sin embargo, de la que en el presente supuesto carecía la demandante de amparo. La concesión es un prius y sin la misma no cabe hablar de derecho, ni en este caso de sanción, puesto que la Administración, a través del acto impugnado, se ha limitado a restablecer la legalidad conculcada. No puede ser calificada de sancionadora la medida que se adopta para restablecer la legalidad conculcada frente a aquel que, por no haber cumplido los requisitos establecidos para el desarrollo de determinada actividad, no ha adquirido el derecho a llevarla a cabo y, no obstante, la emprende.

Pretendida lesión del derecho a emitir libremente información (art. 20.1 a) yd) $C E$ )

- Sostiene la recurrente que la interrupción de las emisiones y la clausura de los equipos para su realización vulnera los derechos reconocidos en el art. 20.1 a) y d) CE, pues, de un lado, se condicionan el ejercicio de estas libertades a una previa autorización no prevista ni regulada por Ley Orgánica, y, de otro, se impide materialmente su ejercicio por falta de autorización administrativa cuyo procedimiento de obtención no se encuentra plasmado en norma positiva alguna.

- El TC entiende que las medidas adoptadas no vulneran los derechos invocados, pues resulta evidente que la modalidad de radio que pretende desarrollar la demandante de amparo, está regulada en nuestro ordenamiento jurídico, sujetándose a un procedimiento administrativo al que no ha querido someterse.

- Y además el Alto Tribunal señala: "Aun si se aceptara la tesis actora de que la materia debería estar regulada por Ley Orgánica, el carácter puramente ordinario de la misma no autoriza a incumplirla. Una cosa es la posibilidad que tiene el afectado por un acto de aplicación de una Ley que, a su juicio, debería ser Orgánica por exigirlo la Constitución, para buscar ante el Tribunal, la protección jurisdiccional del derecho que cree afectado por la insuficiencia de rango de la regulación legal, y otra bien distinta, que, erigiéndose en 
JURISPRUDENCIA

Juez de la constitucionalidad de esa regulación, decida ignorarla por entero, $\mathrm{y}$, tomando pretexto de una actuación administrativa impugnarla ante nosotros, en abstracto, como causa remota de la decisión de la Administración".

FALLO: Denegar el amparo solicitado.

\section{SENT. No 120/1991, DE 3 DE JUNIO. SALA SEGUNDA. RECURSO DE AMPARO No 1695/1988. ALVARO RODRIGUEZ BEREIJO.}

OBJETO: Interpuesto contra los Autos de la Sala Segunda de lo Contencioso-Administrativo de la Audiencia Territorial de Valencia, de 15 de julio de 1.988 y de la Sala Primera de los Contencioso-Administrativo de la misma Audiencia, de 27 de septiembre de 1.988, por supuesta infracción del artículo $24.1 \mathrm{CE}$ por estimar que no se ha observado en la ejecución de unas Sentencias aquello que éstas habían reconocido y declarado. En concreto, la cuestión planteada tiene su origen en la solicitud de colegiación que los demandantes de amparo, de nacionalidad argentina, dirigieron al Colegio Oficial de Odontólogos y Estomatólogos de la Tercera Región (Valencia), una vez conseguida del Ministerio de Educación y Ciencia la previa homologación de sus respectivos títulos de odontólogos obtenidos en su país.

Las solicitudes fueron denegadas por el Colegio por no constar el previo permiso de trabajo de extranjeros conforme lo dispuesto en la Ley Orgánica 7/1985, de 1 de julio, lo que dio lugar a que reclamaran el reconocimiento de su «derecho a ser colegiados sin condicionamiento alguno", esto es, sin la previa exigencia del permiso de trabajo, recayendo Sentencias estimatorias reconociendo «el derecho a obtener la colegiación solicitada".

El Colegio, en ejecución de los mandatos judiciales, procedió a la colegiación pero sin ejercicio, por no constar en su expediente «el permiso de trabajo para su legal ejercicio de la odontología», lo que dio lugar a que los recurrentes, al considerar que dicha ejecución no se ajustaba a los términos del fallo de las Sentencias dictadas, solicitaran de las correspondientes Salas de los Contencioso-Administrativo de la Audiencia Territorial de Valencia «el fiel cumplimiento de la Sentencia (...) colegiándolos en calidad de ejercientes».

El presente recurso se dirige contra los Autos que desestimaron dichas reclamaciones resolviendo que las decisiones del Colegio eran 
conformes a lo acordado en las Sentencias, y se solicita del TC que declare la nulidad de dichas resoluciones judiciales y reconozca el derecho de los recurrentes «a que la ejecución de las Sentencias obtenidas consista en la incorporación al Colegio (...) como lo tengan ellos solicitado estableciendo el derecho a cambiar las condiciones y calidades de su incorporación cuantas veces lo deseen y lo permita el Estatuto Reglamentario de los Colegios Oficiales de Odontólogos y Estomatólogos de España».

FALLO: Denegar el amparo solicitado, puesto que, lo que, en definitiva, pretenden los actores por vía del incidente de ejecución de Sentencia, y mediante el amparo ante el TC, es obtener directamente el reconocimiento de que su derecho a la colegiación, lo es para el ejercicio de la profesión, a su libre decisión y voluntad, al margen de los requisitos que la legislación establece para el ejercicio profesional de los extranjeros en España. Y ello excede claramente de lo acordado en este caso por el órgano judicial y de lo que puede ser concedido por el TC al amparo del derecho constitucional a que se respeten y ejecuten las Sentencias firmes en sus propios términos.

VOTO PARTICULAR: Formulado por D. Eugenio Díaz Eimil.

\section{SENT. N ${ }^{\circ}$ 125/1991, DE 6 DE JUNIO. PLENO. RECURSO DE INCONSTITUCIONALIDAD $\mathbf{N}^{\circ}$ 815/1985. MIGUEL RODRIGUEZ-PIÑERO Y BRAVO-FERRER.}

OBJETO: Interpuesto por el Gobierno de la Nación contra la Disposición final tercera, apartado a), de la Ley 9/1985, de 24 de mayo, de la Generalidad de Cataluña sobre modernización de la empresa familiar agraria, que prevé la aplicación a las empresas familiares establecidas en la Ley catalana «de cualesquiera otros beneficios establecidos en relación con las empresas familiares».

MATERIA: Compatibilidad de los beneficios establecidos por la Ley catalana con otros en relación con las empresas familiares.

- El Abogado del Estado basa su impugnación en afirmar que la Ley catalana carece de toda aptitud para regular el ámbito y efectos de la Ley estatal y menos para ampliar la aplicación de los beneficios instituidos por la Ley estatal en fomento de un tipo bien definido de empresa familiar por la Ley 49/1981, que no coincide con el definido por la Ley catalana 9/1985. 
JURISPRUDENCIA

- Tanto el Parlamento de Cataluña como el Abogado de la Generalidad de Cataluña, sostienen que el precepto no tiene el alcance de modificación o alteración de la normativa estatal, sino sólo el de determinar la compatibilidad de los propios beneficios que la Ley autonómica otorga con los que puedan obtenerse a través de otras disposiciones, dando por supuesto que se cumplan las condiciones que esas normas establecen.

- El TC entiende que cabe interpretar que el precepto no amplía el ámbito o los efectos de la Ley estatal, sino supone sólo el reconocimiento de que las empresas familiares agrarias de Cataluña que se acojan a los beneficios de la Ley catalana, puedan gozar también de cualesquiera otros beneficios que hay previsto el Estado en uso de sus competencias siempre que reúnan los requisitos y presupuestos que para cada caso consigne la Ley estatal.

FALLO: Desestimar el recurso de inconstitucionalidad.

\section{SENT. No 129/1991, DE 6 DE JUNIO. SALA PRIMERA. RECURSO DE AMPARO No $1372 / 1988$. LUIS LOPEZ GUERRA.}

OBJETO: Interpuesto frente a la Sentencia de 19 enero de 1987 de la Sala Segunda de lo Contencioso-Administrativo de la Audiencia Territorial de Madrid que declara nulo un acuerdo de adjudicación de plaza en el INSALUD. El demandante de amparo alega indefensión causada por no haber sido llamado, de modo personal y directo, al proceso contencioso-administrativo en que se dilucidaban cuestiones que le afectaban directamente y ello a pesar de ser fácilmente identificable a partir de la propia demanda iniciadora del proceso y del expediente obrante en el mismo.

FALLO: Estimar el recurso de amparo y, en consecuencia:

1. Anular la Sentencia impugnada.

2. Reconocer el derecho del recurrente a ser emplazado personalmente en el recurso contencioso-administrativo.

3. Restablecer al recurrente en la integridad de su derecho y para ello retrotraer las actuaciones del mencionado recurso al momento inmediatamente posterior al de su interposición, debiéndose emplazar personalmente al solicitante de amparo para que pueda comparecer y defender sus derechos. 


\section{SENT. N' 130/1991, DE 6 DE JUNIO. SALA PRIMERA. RECURSO DE AMPARO No $1879 / 1990$. FRANCISCO TOMAS Y VALIENTE.}

OBJETO: Promovido por la Universidad de Valencia contra Sentencia de 12 de junio de 1990 de la Sala Tercera del Tribunal Supremo, que confirmó en apelación la dictada por la Sala Segunda de lo Contencioso-Administrativo de la entonces Audiencia Territorial de Valencia, de 11 de diciembre de 1987, sobre aprobación de los Estatutos de la Universidad. La Universidad demandante de amparo denuncia la violación de su derecho fundamental de autonomía universitaria (art. 27.10 CE); violación imputable de modo inmediato y directo a las dos resoluciones judiciales impugnadas que anulan el art. 12, párrafo $1 .^{\circ}$, letra c), apartados 1,2 y 3, y párrafo $2 .^{\circ}$ de los Estatutos de la Universidad Valenciana, declarando además que la palabra «Emblema» contenida en el art. 12.1 «es contraria a Derecho y por tanto jurídicamente inaplicable, por falta de idoneidad y sentido correcto en el presente caso y que debe ser sustituida por la de «Escudo» de la Universidad de Valencia, como denominación correcta legal...» (Sent. de la Audiencia Territorial de Valencia de 11 de diciembre de 1987).

FALLO: Otorgar el amparo solicitado y, en consecuencia:

$1^{\circ}$ Anular las Sentencias impugnadas.

$2^{\circ}$ Declarar que la Universidad de Valencia en el legítimo ejercicio de su derecho fundamental de autonomía puede válidamente acordar por el procedimiento legal establecido lo procedente acerca del nombre y características de sus símbolos representativos, siendo en consecuencia válido y conforme a Derecho el contenido del art. 12 de los Estatutos aprobados por el Claustro Constituyente el 6 de mayo de 1985 y, posteriormente, por Decreto del Consell de la Generalidad Valenciana 172/1985, de 28 de octubre.

\section{B.O.E. DE 22 DE JULIO DE 1991. SUPLEMENTO DEL $N^{\circ} 174$}

\section{SENT. No 136/1991, DE 20 DE JUNIO. PLENO. RECURSO DE INCONSTITUCIONALIDAD No $986 / 1985$. MIGUEL RODRIGUEZ-PIÑERO Y BRAVO-FERRER.}

OBJETO: Planteado por el Gobierno de la Nación, contra las expresiones "o definitivas" y "o definitivo" contenidas en las letras a) y b) del art. 46.3 de la Ley 20/1985, de 25 de julio, del Parlamento de 
Cataluña, de prevención y asistencias en materia de sustancias que puedan generar dependencia.

MATERIA: Posible divergencia respecto a la correspondiente regulación sancionadora estatal, válida para todo el territorio nacional, del carácter definitivo de las sanciones previstas en los apartados a) y b) del art. 46.3 de la Ley catalana impugnada.

- El Abogado del Estado reconoce la competencia en la materia de la Comunidad Autónoma y el rango suficiente en la norma sancionadora, pero considera que se establece una sanción, el cierre definitivo de establecimientos, no prevista en la normación correspondiente estatal y que supone introducir divergencias irrazonables y desproporcionadas al fin perseguido respecto al régimen jurídico aplicable en otras partes del territorio, divergencias que entiende incompatibles con el art. 149. 1.1 CE.

- El TC señala que para que pueda operar el límite específico y excepcional del art. 149.1.1 CE, en su función de asegurar la igualdad en el ejercicio de derechos y cumplimiento de deberes constitucionales en todo el territorio del Estado -en este caso la garantía institucional de la libertad de empresa (art. $38 \mathrm{CE}$ ) en relación con el bien constitucionalmente protegido en el art. 139.2 CE-, han de darse dos condiciones, en primer lugar, la existencia de un "esquema sancionatorio estatal", que afecte a estos derechos y deberes constitucionales, y en segundo lugar, que la normativa sancionadora autonómica suponga una divergencia cualitativa sustancial respecto a esa normativa sancionadora estatal que produzca una ruptura de la unidad en lo fundamental del esquema sancionatorio que pueda calificarse además de irrazonable y desproporcionada al fin perseguido por la norma autonómica.

- En relación con el elemento de comparación, la norma cuestionada no debe ser elemento dentro de la materia de defensa del consumidor, como hace el Abogado del Estado, sino el correspondiente a la materia sanitaria, dado que se trata de la prevención y asistencia en materia de sustancias que pueden generar dependencia, y cuyo consumo no se trata de ordenar, sino precisamente de eliminar, siendo ilícita, salvo excepciones, su comercialización. Y existen diversas disposiciones estatales en materia sanitaria en que está prevista la clausura definitiva de centros y establecimientos por requerirlo la salud colectiva o por incumplimiento de los requisitos exigidos para su instalación y funcionamiento. Por tanto, dada la equivalencia de resultados, no cabe constatar que exista una ruptura del esquema sancionatorio estatal que produzca el vedado efecto desigualatorio. 
- Además, dada la naturaleza de las infracciones que la legislación catalana toma en consideración - no un tema general de salud pública, sino un tema específico relativo a sustancias que pueden generar dependencia, con el consiguiente riesgo sanitario y social que con la norma autonómica se pretende prevenir, y cuya transcendencia resulta evidente-, la singularidad de la materia objeto de la norma autonómica constituye un fundamento razonable susceptible de eliminar la calificación de arbitraria o desproporcionada al fin perseguido de la eventual diferencia en el grado de sanción establecida, en su caso, respecto del régimen jurídico sancionatorio aplicable en todo el Estado, al no existir una previsión sancionatoria estatal con ese grado de especificidad. Por tanto, de existir, como sostiene el Abogado del Estado, un "salto sancionador cualitativo» la ruptura de la unidad del esquema sancionatorio no introduce divergencias irrazonables y desproporcionadas al fin perseguido respecto a las sanciones previstas en la normación del Estado.

FALLO: Desestimar el recurso de inconstitucionalidad.

\section{SENT. $\mathbf{N}^{\circ}$ 143/1991, DE 1 DE JULIO. SALA SEGUNDA. RECURSO DE AMPARO $\mathbf{N}^{\circ} 37 / 1989$. ALVARO RODRIGUEZ BEREIJO.}

OBJETO: Presentado contra las Sentencias de la Audiencia Provincial de Granada y del Tribunal Supremo de 3 de octubre de 1985 y 25 de noviembre de 1988, respectivamente, que condenan al recurrente por un delito de desacato, por entender el demandante de amparo que dichas Sentencias son contrarias a la libertad de expresión y a la actividad sindical. El fondo del asunto no es otro que el de la legitimidad de la difusión de un comunicado sindical sobre la imputación a los órganos de dirección de la cárcel de puestas indebidas en libertad, situación que afecta tanto a quienes prestan sus servicios profesionales en el establecimiento penitenciario como a la sociedad en general. Así quedan imbricados las libertades de expresión y de información y el derecho a la actividad sindical, manifestado en la difusión de comunicados relativos al mundo del trabajo de quien los emite. No sólo, pues, habrá que tener presente el marco constitucional del art. $20 \mathrm{CE}$, sino también el propio del art. $28 \mathrm{CE}$, puesto que en este caso el recurrente es un funcionario público y cargo sindical, y, en consecuencia, no puede olvidarse que la acción sindical de los funcionarios está sometida a ciertas peculiaridades (art. 103.3 CE).

FALLO: Otorgar el amparo solicitado, puesto que el derecho a comunicar o recibir libremente información, como regla general, debe 
JURISPRUDENCIA

prevalecer siempre que, como en este caso, la información transmitida sea veraz y esté referida a asuntos públicos que son del interés general por las materias a que se refieren y por las personas que en ellos intervienen, $\mathrm{y}$, en consecuencia corresponde:

$1 .^{\circ}$ Reconocer al recurrente su derecho a la libertad de información en el ejercicio de su actividad sindical.

2. ${ }^{\circ}$ Anular las Sentencias impugnadas.

\section{SENT. $\mathbf{N}^{\circ}$ 145/1991, DE 1 DE JULIO. SALA SEGUNDA. \\ RECURSO DE AMPARO No 175/1989. MIGUEL RODRIGUEZ-PIÑERO Y BRAVO-FERRER.}

OBJETO: Interpuesto frente a la Sentencia de la Sala Primera del Tribunal Central de Trabajo de 18 de noviembre de 1988, que revoca la dictada por la Magistratura de Trabajo núm. 3 de Madrid, de 1 de febrero de 1988, que declaró discriminatoria la existencia de un salario inferior para las Limpiadoras que para los Peones establecido en el Convenio Colectivo aplicable al Hospital Provincial «Gregorio Marañón» dependiente de la Consejería de Sanidad y Bienestar Social de la Comunidad de Madrid. Se invoca la vulneración del art. 14 CE.

FALLO: Conceder el amparo solicitado, puesto que la Sentencia impugnada del Tribunal Central de Trabajo, al revocar la Sentencia de la Magistratura de Trabajo que había declarado la existencia de discriminación entre las recurrentes y otros trabajadores que realizaban «exactamente las mismas funciones», ha permitido que subsista la situación de discriminación social en que se encontraban y, consecuentemente, ha lesionado el derecho de las recurrentes a no ser discriminadas por razón de sexo que les reconoce el articulo $14 \mathrm{CE}$ y, en consecuencia corresponde:

$1 .^{\circ}$ Reconocerles el derecho a no ser discriminadas en su salario por razón de sexo.

2. ${ }^{\circ}$ Anular la Sentencia impugnada.

\section{SENT. N $^{\circ}$ 146/1991, DE 1 DE JULIO. SALA SEGUNDA. \\ RECURSO DE AMPARO $\mathbf{N}^{\circ} 450 / 1989$. JOSE LUIS DE LOS MOZOS Y DE LOS MOZOS.}

OBJETO: Interpuesto contra el Auto de la Sala Tercera del Tribunal Supremo de 23 de enero de 1989, dictado en procedimiento de tasación de costas. Se invoca la vulneración del art. 24.1 CE. 
FALLO: Desestimar el recurso de amparo pues plantean los solicitantes de amparo una cuestión en todo punto análoga a la conocida y resuelta por la STC 147/1989 (ya reseñada con anterioridad. Vid. reseñas del cuarto trimestre de 1989, REALA, $\left.n^{\circ} 244\right)$ en la que se fundamenta una decisión igualmente desestimatoria.

B.O.E. DE 29 DE JULIO DE 1991. SUPLEMENTO DEL N 180

\section{SENT. N 147/1991, DE 4 DE JULIO. PLENO. CONFLICTOS POSITIVOS DE COMPETENCIA 384/1985, 407/1985 Y 340/1989 (ACUMULADOS). EUGENIO DIAZ EIMIL.}

OBJETO: Promovidos, respectivamente, por el Consejo Ejecutivo de la Generalidad de Cataluña, por la Junta de Galicia, y por el Gobierno de la Nación, en relación con el Real Decreto 2349/1984, de 28 de noviembre, por el que se regula la pesca de "Cerco" en el caladero nacional, y con la Orden del Departamento de Agricultura, Ganadería y Pesca de la Generalidad de Cataluña de 15 de diciembre de 1988 , en la que se fija un período de veda, para la modalidad de pesca de cerco (meses de enero y febrero de 1988), en los distritos marítimos de San Carlos de la Rápita, Tortosa y Tarragona.

\section{MATERIAS:}

A) El Estado, en el RD 2349/1984, no desborda el contenido de competencias que ostenta sobre la pesca maritima y las bases de la ordenación del sector pesquero, ni restringe indebidamente el ámbito de competencias de las CCAA actoras, excepto en sus arts. 16, 17 y 14 párrafo segundo.

\section{1) Impugnación del $R D 2349 / 1984$ por la Generalidad de Cataluña.}

- La C.A. de Cataluña considera que el RD invade la competencia de desarrollo legislativo y ejecución que le atribuye, en el marco de la legislación básica estatal, el art. 10.1.7 de su Estatuto en materia de "ordenación del sector pesquero", en relación con el art. 149.1.19, atributivo de competencia al Estado sobre "pesca marítima".

- En reivindicación de esta competencia, la Comunidad de Cataluña, suplica la nulidad total del Decreto con fundamento sustancial en los dos argumentos siguientes: 
a) Alcance de la concreción de las normas básicas

- La CA catalana entiende que el Decreto carece de aptitud para merecer la calificación de norma básica, puesto que incide en un exceso de concreción que impide ulterior desarrollo autonómico, recae sobre una modalidad de pesca muy concreta, que es impropia, por su especificidad, para ser objeto de normación básica, y establece un régimen diferenciado para áreas geográficas singulares - Mediterráneo y Cantábrico- que es incompatible con las condiciones de uniformidad exigibles a toda legislación básica.

- Frente a este razonamiento, el TC señala que las reglas y actos que merezcan la calificación de básicos no pierden tal consideración aunque desciendan a un plano de detalle y minuciosidad, que dificulte o incluso, impida el desarrollo normativo autonómico o la adopción de determinados actos de ejecución, puesto que ello sólo determinará la invasión de la competencia de la Comunidad si en el caso concreto el detalle y la minuciosidad de la reglamentación estatal, o el acto de ejecución realizado por instancias centrales, no goza de cobertura justificativa suficientes por no responder a la necesidad de asegurar los fines de unidad normativa mínima que legitima la competencia básica estatal. Y en este caso, la disposición recurrida no excede el ámbito constitucionalmente posible para las normas básicas, porque ni tal técnica resulta extensible a la totalidad de los preceptos del Decreto ni cuando así lo es, desborda el Estado el contenido de su competencia. Por otro lado, tampoco cabe sostener que la disposición impugnada no posee naturaleza de norma básica por establecer una regulación distinta para el área mediterránea del caladero nacional que para otras, puesto que la presencia de una finalidad unitaria no impide que, cuando sea menester, en la persecución de un objetivo, se contemplen situaciones distintas de manera también distinta como ocurre con las peculiaridades de los fondos en la plataforma mediterránea.

b) Contradicción con el $\mathrm{RD}$ de traspaso de funciones y servicios en materia de "ordenación del sector pesquero"

El Decreto impugnado contiene preceptos que contradicen artículos correlativos del RD 665/1984, de 8 de febrero, de traspaso a Cataluña de funciones y servicios del Estado en materia de "ordenación del sector pesquero", que deben tener valor interpretativo de las competencias asumidas en el Estatuto. 
El TC también desestima este razonamiento al entender que los Reales Decretos de transferencia no atribuyen ni reconocen competencias sino que traspasan servicios, funciones e instituciones; no son normas determinantes del sistema constitucional de distribución de competencias, compuesto exclusivamente por la Constitución, los Estatutos y, en su caso, las demás disposiciones atributivas de competencias, cuyas prescripciones no pueden ser alteradas ni constreñidas por las disposiciones de los Decretos de traspasos; en este sentido, las competencias son indisponibles por las Administraciones, lo que impide hacer prevalecer una presunta voluntad, fruto del acuerdo formalizado en los Decretos de transferencias, sobre el sentido objetivo de las normas constitucionales y estatutarias. $\mathrm{Y}$ a tal respecto materias como el establecimiento de zonas de veda y la fijación de fondos máximos y de cuotas de captura, así como la reglamentación de las artes, atañe a la protección del recurso natural objeto de pesca y corresponde, en exclusiva, al Estado, mientras que otros aspectos, como los diseñados en los arts. 10, 11 y 13 del Decreto, se integran en la competencia estatal para dictar bases de la ordenación del sector pesquero y ordenar los términos en que debe producirse el desarrollo autonómico.

\section{2) Impugnación del RD 2349/1984 por la Junta de Galicia.}

Alcance de la supletoriedad del Derecho estatal.

- La Junta de Galicia centra sus alegaciones en la indebida supletoriedad del Derecho estatal hasta que las Comunidades Autónomas regulen la materia en el ejercicio de sus propias competencias, y con tal fundamento impugna las Disposiciones adicionales primera y segunda, en relación con los arts. 14, párrafo segundo, 16 y 17 del RD, en las que a su juicio se emplea una técnica que desvirtúa el verdadero alcance de la supletoriedad del Derecho estatal, establecida en el art. 149.3 de la Constitución en cuanto que esa supletoriedad debe entenderse referida al derecho estatal "globalmente considerado en su función de Derecho común y no a la producción normativa especial o sectorial" o, dicho de otra manera, "el art. 149.3 entiende la supletoriedad como referida al Derecho y no a las Leyes estatales".

- El TC señala que hay que «reducir el concepto de supletoriedad a sus correctos términos de función, cuya operatividad corresponde determinarse a partir de la norma reguladora del ámbito material en el que se va a aplicar el Derecho supletorio y no desde éste, es decir, como función referida al conjunto del ordenamiento 
jurídico, cuyo valor supletorio debe obtenerse por el aplicador del Derecho a través de las reglas de interpretación pertinentes, incluida la vía analógica, y no ser impuesta directamente por el legislador desde normas especialmente aprobadas con tal exclusivo propósito para incidir en la reglamentación jurídica de sectores materiales en los que el Estado carece de título competencial específico que justifique dicha reglamentación, puesto que esa carencia, según ha establecido la doctrina referida, no puede ser suplida con la conversión de la regla de la supletoriedad en cláusula universal atributiva de competencia".

- En este línea, el Alto Tribunal entiende que hay que: "Considerar viciadas de incompetencia y, por ello, nulas las normas que el Estado dicte con el único propósito de crear derecho supletorio del de las Comunidades Autónomas en materias que sean de la exclusiva competencia de éstas, lo cual no es constitucionalmente legítimo cuando todos los Estatutos de Autonomía atribuyen a las Comunidades la competencia como exclusiva y en un mismo grado de homogeneidad. Esto supone que en cada conflicto en el que una Comunidad reivindique su competencia frente a dicha clase de normas estatales tendría que examinarse si se trata de competencias que corresponden en exclusiva a todas las Comunidades Autónomas, pues si así no fuese el Estado tendría competencia para dictarlas en relación con aquellas Comunidades que no hubieran adquirido tal exclusividad. Por lo tanto, a la resolución de dicho conflicto se añadiría la dificultad de examinar con detalle todos y cada uno de los Estatutos de Autonomía con el fin de determinar si la competencia exclusiva viene o no atribuida con alcance universal a todas las Comunidades, puesto que de no ser así no podría declararse nula por incompetencia la norma estatal sino únicamente como inaplicable en el territorio de la Comunidad que, habiendo planteado el conflicto, resultase tener la competencia exclusiva sobre la materia; debe por ello evitarse un pronunciamiento de nulidad total que además afectaría a Comunidades que no han impugnado la norma estatal, quizás por seguir la política legislativa de considerar apropiada la normativa estatal y, por tanto, decidir el aplicarla mientras no consideren oportuno desplazarla a un grado supletorio mediante la aprobación de una reglamentación propia.

Ello conduce a estimar que no procede la aplicación con carácter supletorio de los arts. 14, párrafo segundo, 16 y 17 a las Comunidades Autónomas de Galicia y Cataluña, en términos de las disposiciones adicionales primera y segunda. 
$\mathrm{El}$ art. 14, párrafo segundo, queda fuera de la competencia del Estado la fijación de bases de ordenación del sector pesquero, como resulta tanto de la materia que regula - mera localización del descanso obligatorio, cuya extensión ya viene determinada con carácter básico en el primer párrafo del mismo artículo-, como del reconocimiento expreso que, de la ausencia de carácter básico supone la propia declaración de mera eficacia supletoria que se hace en la citada disposición adicional segunda.

En cuanto a los arts. 16 y 17 no pueden interpretarse en otro sentido que en el de establecer una prohibición que incide en la 'pesca en aguas interiores' y 'pesca fluvial' -art. 148.1.11 CE-, materias que han sido asumidas por la competencia exclusiva de Cataluña -art. 9.1.17 EAC - y por Galicia -art. 27.15 EAG-, sobre las cuales el Estado no invoca título competencial alguno que no sea la cláusula de supletoriedad del art. 149.3 CE, la cual, según dejamos razonado, no es por sí sola título idóneo que autorice al Estado para imponer esa prohibición, ni siquiera con los efectos supletorios que le asigna la disposición adicional primera del RD impugnado, debiendo, en mérito a ello declarar que dicho precepto no es aplicable en los territorios de las referidas Comunidades».

B) El establecimiento de un periodo de veda para la modalidad de pesca de cerco en el litoral catalán invade la competencia estatal

1) Impugnación por el Gobierno de la Nación de la Orden del Departamento de Agricultura, Ganadería y Pesca de la Generalidad de Cataluña, de 15 de diciembre de 1988.

\section{FALLO:}

1. ${ }^{\circ}$ Declarar que corresponde al Estado la titularidad de las competencias ejercidas en el RD estatal y en la Orden de la Generalidad de Cataluña impugnados, a excepción de lo dispuesto en las Disposiciones adicionales primera y segunda del RD estatal, en cuanto declaran de aplicación supletoria los arts. 16, 17 y párrafo segundo del art. 14, en lo que se refiere a las aguas interiores, preceptos que declaramos inaplicables, directa o supletoriamente, en las Comunidades Autónomas de Cataluña y Galicia.

2. ${ }^{\circ}$ Anular, en consecuencia, la citada Orden de la Generalidad de Cataluña de 15 de diciembre de 1.988. 
JURISPRUDENCIA

\section{SENT. No 148/1991, DE 4 DE JULIO. PLENO. RECURSO DE INCONSTITUCIONALIDAD N $982 / 1985$. VICENTE GIMENO SENDRA.}

OBJETO:

Interpuesto por el Presidente del Gobierno contra determinados preceptos de la Ley de Canarias 3/1985, de 29 de julio, de Medidas Urgentes en materia de Urbanismo y Protección de la Naturaleza.

MATERIAS: Facultades autonómicas de suspensión de actos de edificación y de otros usos del suelo en defensa del medio ambiente.

- La Ley impugnada atribuye a la C.A. de Canarias diversas facultades de suspensión de actos de edificación y de otros usos del suelo, en defensa del medio ambiente. Su art. 3 detalla que la competencia para decretar la suspensión cautelar regulada en el art. 2 corresponde al Gobierno de Canarias, el cual puede bien transferirla o delegarla a un ente territorial, bien delegar su ejercicio en la Consejería que ejerza las competencias en materia de ordenación del territorio, urbanismo y medio ambiente.

- El Presidente del Gobierno impugna los artículos 2 y 3 de la Ley Canaria en su integridad por considerar que vulneran la autonomía municipal protegida por el artículo 137 de la Constitución, tanto directamente, como por contradecir las normas básicas que la Ley de Bases de Régimen Local de 1985 dedican a regular la suspensión de acuerdos de las Corporaciones Locales.

1) Art. 2 ap. 2: Suspensión de actos que amparen el uso del suelo y la edificación en protección del ambiente cultural o natural.

- La potestad de suspensión que crea el ap. 2 del art. 2 recae sobre "el acto o actos que amparen el uso del suelo y la edificación», y se justifica en que dichós usos o edificaciones «puedan hallarse incursos en algunos de los casos contemplados en el art. 73 de la Ley del Suelo". Este precepto de la legislación estatal ordena que las construcciones habrán de adaptarse, en lo básico, al ambiente en que estuvieran situadas, ya sea éste cultural, o natural. La decisión de suspender es autónoma, y no un instrumento cautelar puesto al servicio de una posterior resolución autonómica como la prevista en el apartado 1.

- El TC entiende que el art. 2.2 se encuentra redactado en términos amplios, que permiten que las facultades de suspensión dirigidas al control del "acto o actos que amparen el uso del suelo y la 
edificación" se ejerzan respecto de actos autorizatorios que no se encuentran sometidos al sistema de impugnación establecido por los arts. 65 y 66 LBRL. El supuesto más importante, aunque no el único, lo ofrecen las autorizaciones para llevar a cabo edificios e instalaciones de interés público que hayan de emplazarse en el medio rural, así como edificios aislados destinados a vivienda familiar en lugares en los que no exista posibilidad de formación de un núcleo de población, que los arts. 86 y 85 LS ponen en manos de la $\mathrm{CA}$, con carácter previo a la licencia municipal, y que ha desarrollado y modulado la Ley de Canarias 5/1987, de 7 de abril, sobre ordenación urbanística del suelo rústico. Es evidente que nada hay, ni en el contenido esencial de la autonomía local garantizado directamente por el art. $137 \mathrm{CE}$, ni en su contenido básico establecido por la LBRL, que impida que el Gobierno de Canarias pueda suspender las autorizaciones emitidas por los órganos de su Administración, con el fin de revisar su adecuación al art. 73 LS. Los intereses públicos que anidan en los recursos naturales, paisajísticos e histórico-artísticos de las islas Canarias deben ser protegidos por los poderes públicos, y tales intereses en la protección del medio ambiente y del patrimonio histórico se encuentran incluidos en el círculo confiado a la competencia de la CA por su Estatuto de Autonomía y por la LOTRACA; pero tales competencias sólo pueden ser ejercidas en el modo dispuesto por el art. 2.2 de la Ley recurrida, en tanto en cuanto la medida de suspensión de allí se crea no venga a complementar las facultades de impugnación de actos locales en términos que resulten incompatibles con lo dispuesto por los arts. 65 y 66 LBRL, desfigurando el modelo de autonomía local establecido en dicha Ley estatal.

- Pero el TC también indica que dado el grado de indeterminación de los conceptos jurídicos empleados por el art. 73 LS, y su amplio radio de aplicación a cualquier lugar, hay que afirmar que la facultad de suspensión que habilita el ap. 2 del art. 2 linda con el control de oportunidad, y desde luego, podría constituir uno de esos controles genéricos e indeterminados que infringirían la garantía institucional de la autonomía local si se utilizara para suspender actos definitivos y ejecutorios dictados por un Municipio.

2) Art. 2 ap. 1: Suspensión cautelar de operaciones de edificación y otros usos del suelo por motivos de protección ambiental.

— El ap. 1 del art. 2 prevé que la suspensión decretada por la Comunidad Autónoma recaiga sobre «los actos de uso del suelo y de la edificación ejercitados por particulares y empresas públicas o privadas, aun cuando dichos actos estén amparados por licencia o 
JURISPRUDENCIA

autorización previa, otorgada de acuerdo con su legislación especifica». Esta suspensión se configura como una medida cautelar dirigida a preservar la eficacia de una posterior resolución autonómica que ha de consistir, ora en la declaración de un espacio natural protegido, ora en la aprobación de un plan especial de protección ambiental. La suspensión se decretará, de oficio o a instancia de parte, una vez incoado el correspondiente expediente de declaración de protección o de aprobación del plan.

- El TC señala que este precepto no establece un instrumento para controlar administrativamente la legalidad de los actos municipales. La facultad de suspensión que acuña el precepto se proyecta directamente sobre las operaciones de edificación y otros usos del suelo, se encuentren o no autorizados por un previo acto administrativo, y dicha licencia o autorización previa, cuando exista, puede haber sido otorgada por una Corporación local o por otras Administraciones públicas. El presente recurso se dirige contra el ap. 1 del art. 2 tan sólo en cuanto se aplique para suspender operaciones autorizadas por un acuerdo proveniente de una Corporación local.

- Aun cuando la CA, en virtud del art. 2.1., suspendiera obras u otros usos del suelo amparados por una licencia local, suspendiendo por ende los efectos jurídicos del acuerdo, adoptado por la entidad municipal, provincial o insular, no estaría ejerciendo un control de la legalidad de dicho acuerdo. El fundamento de la medida de suspensión establecida por el art 2.1. de la Ley impugnada no es la defensa de la legalidad, pues la suspensión afecta a todos los actos autorizatorios comprendidos en el área de actuación contemplada, al margen de si se adecúan o no a la legalidad vigente, sea o no la urbanística. En puridad, la premisa sobre la que opera el art. 2.1. es que las licencias han de ser conformes con los planes proyectados y demás determinaciones vigentes; pues su punto de referencia no lo ofrecen las normas en vigor, sino las futuras, a saber: las que vengan impuestas sobre el espacio acotado como consecuencia de la prevista declaración de protección, de conformidad con la Ley estatal 4/1989, sobre conservación de espacios naturales (LENFF), o como consecuencia del oportuno plan especial, de conformidad con los arts. 17 y ss. LS. La finalidad de esta suspensión cautelar es evitar el riesgo de que las obras y aprovechamiento que se lleven a cabo durante el tiempo empleado en tramitar y aprobar definitivamente la disposición protectora, no generen o consoliden situaciones que, aunque conformes con la ordenación aún vigente, sean contradictorias con las disposiciones y las limitaciones que se vayan a aprobar para proteger el espacio natural, lo que dificultaría y encarecería, cuando no impediría, la aplicación y efectividad del futuro plan o espacio protegido. 
- Al no encontrarnos ante una técnica para el control administrativo de la legalidad de los acuerdos adoptados por las Corporaciones no cabe aceptar las alegaciones del Presidente del Gobierno. En primer lugar, son inaplicables a este supuesto las normas básicas sobre impugnación de actos locales que establece la LBRL. Y, en segundo lugar, al constituir la suspensión cautelar un instrumento que sirve a la defensa de competencias propias de la Administración autonómica, no puede decirse que su existencia entrañe un atentado a la autonomía local.

3) Art. 2.1. párrafo 2.: Anulación de licencias por el procedimiento de revisión de oficio de actos administrativos.

- El art. 2.1. párrafo $2 .^{\circ}$ dispone que, una vez acordada la suspensión de las edificaciones y otros usos en la zona que se proyecta someter a una declaración o a un plan de protección ambiental, la medida podrá ser levantada tras comprobar que no se provocan daños al área objeto del expediente. La segunda frase del párrafo añade: «En otro caso podrá procederse a la anulación de la licencia por el procedimiento establecido para la revisión de oficio de los actos administrativos».

- El TC deja bien claro que la potestad que otorga este precepto a la Administración autonómica no puede ejercerse sobre actos emitidos por las entidades locales, puesto que la revisión, como todo acto de género revocatorio, sólo puede recaer sobre los actos emitidos por las entidades locales, puesto que, la revisión, como todo acto de género revocatorio, sólo puede recaer sobre los actos que han sido dictados por la misma Administración que emite el acto de contrario imperio, o al menos que ejerce lícitamente la misma competencia en cuyo ejercicio fue dictado. El enjuiciamiento de la ilegalidad de las licencias municipales corresponde a los Tribunales, al conocer de las impugnaciones que, si son interpuestas por una Comunidad Autónoma, deberán canalizarse por las vías previstas por los arts. 65 y 66 LBRL.

- El párrafo segundo del art. 2.1. es susceptible de una interpretación más restringida que limitaría la anulación por revisión de oficio a las autorizaciones otorgadas por la propia Administración autonómica. Aunque este entendimiento hurtaría a la norma del alcance de las bases estatales que en la actualidad definen con amplitud la autonomía local, no puede evitar finalmente su inconstitucionalidad. Y ello porque haría posible la anulación de licencias por su incompatibilidad con las normas que definirán, en el futuro, el régimen de protección del espacio natural; normas que inevitablemente 
JURISPRUDENCIA

se encontrarán todavía en tramitación, pues serán un mero proyecto de normas futuras o, a lo sumo, habrán entrado en vigor con posterioridad al momento en que se otorgó la licencia revisada. Por ello, y con independencia de que al amparo de la legislación administrativa estatal puede la CA someter a revisión de oficio sus propias licencias o adoptar las medidas pertinentes de ejecución del plan o de la declaración de espacio protegido, se hace forzoso concluir en que dicha regulación contradice frontalmente el régimen común y básico establecido por el art. 109 y ss. de la LPA, por lo que ha de ser declarada nula.

4) Art. 3: Organos que pueden ejercer las citadas potestades autonómicas.

- Las conclusiones alcanzadas al conocer del art. 2 de la Ley se propagan automáticamente a lo dispuesto en su art. 3, el cual se limita a determinar los órganos que pueden ejercer las potestades acuñadas en el art. 2. Por lo que el Gobierno de Canarias sólo podrá ejercer, o en su caso transferir o delegar, las facultades enunciadas en el art. 2 de la Ley impugnada, en términos que no invadan el ámbito que a la autonomía local garantizan la Constitución y la LBRL, en los términos expuestos por la presente Sentencia.

FALLO:

1. ${ }^{\circ}$ Declarar la inconstitucionalidad y consiguiente nulidad de la última frase del párrafo segundo del art. 2.1. de la Ley de Canarias impugnada.

2. ${ }^{\circ}$ Declarar que su art. 2.2. no es inconstitucional en los términos expuestos en el fundamento jurídico $4 .^{\circ}$ de esta Sentencia.

3. ${ }^{\circ}$ Desestimar el recurso en todo lo demás.

\section{SENT. No 149/1991, DE 4 DE JULIO. PLENO.}

RECURSOS DE INCONSTITUCIONALIDAD 1689, 1708, 1711, $1715,1717,1723,1728,1729$ Y 1740/1988 (ACUMULADOS). FRANCISCO RUBIO LLORENTE.

OBJETO: Interpuestos contra la ley 22/1988, de 28 de Julio, de Costas. Han sido recurrentes la Xunta de Galicia, el Consejo de Gobierno de las Islas Baleares, el Gobierno Vasco, el Parlamento de Cataluña, el Consejo de Gobierno de la Diputación Regional de Cantabria, el Consejo Ejecutivo de la Generalidad de Cataluña, el Gobierno de Canarias, el Gobierno Valenciano y un grupo de 50 Diputados. 
MATERIAS: Estudios de la constitucionalidad de Ley de Costas.

- La inconstitucionalidad que los recurrentes denuncian se argumenta, en cada uno de los recursos y respecto de cada uno de los preceptos, mediante razones diversas, que son analizadas individualizadamente y en detalle en la sentencia (a la que por su evidente importancia me remito), sin que puedan ser aquí abordadas pormenorizadamente, puesto que su exposición haría excesivamente prolija esta reseña.

- El motivo común y fundamental que todos los recurrentes aducen para sostener la inconstitucionalidad de los artículos que integran el cuerpo de la Ley, utilizado en particular frente a cada uno de ellos, a veces como argumento único y directo, a veces sólo de modo indirecto o en unión de otros, es, sin embargo, el de que mediante el establecimiento de estas normas el Estado invade la competencia exclusiva de las Comunidades Autónomas sobre ordenación del territorio y urbanismo, e incluso la autonomía municipal.

FALLO: Estimar parcialmente los recursos de inconstitucionalidad interpuestos y, en consecuencia:

1. ${ }^{\circ}$ Declarar que son inconstitucionales y consiguientemente nulos los articulos:

26.1 (y, en consecuencia las Disposiciones transitorias cuarta apartado $2 \mathrm{c}$ - y séptima - apartado 1- y Disposición final primera en cuanto atribuyen a la Administración del Estado el otorgamiento de autorizaciones en la zona de protección); 33.4, inciso final; 34 (y, en consecuencia, todas las referencias que a las normas aprobadas de acuerdo con él se hacen en los arts. 47.3, $52.1,53.1,57.2$, Disposición transitoria tercera, apartado 4, y en la Disposición final primera); 35.2, las palabras «de oportunidad u otras"; 110, apartados b) (en cuanto referido a los vertidos de tierra a mar) y 1) (en cuanto se refiere a la inspección y coordinación del cumplimiento de los Tratados Internacionales por las Comunidades Autónomas); 111, apartado 1 d), en cuanto incluye el inciso "sobre acuicultura»; 118 y Disposición adicional quinta, apartado 2, en las palabras "en todo caso".

$2 .^{\circ}$ Declarar que no son inconstitucionales si se interpretan en el sentido que se expone en los fundamentos jurídicos de esta sentencia, que a continuación de cada uno de ellos entre paréntesis se indican, los artículos siguientes: 
JURISPRUDENCIA

25, apartado 3 (f.j. 3.D.c); 33 apartado y 4 , este último respecto del inciso «y se distribuirán de forma homogénea a lo largo de la misma» (f.j. 4.B.c); 44, apartado 1 (f.j. 4.C.a); 55, apartado 1 (f.j. 4.E.c.a); 67 (f.j. 4.G.b); 68 (f.j. 4.G.c); 71, apartado 3 (f.j. 4.G.d); 86 (f.j. 5.C); 110, apartados c), g) e i) (f.j. 7.A, c, g, i); 112 (f.j. 7.A.c); 115 (f.j. 7.C); Disposición transitoria primera, apartado 3 (f.j. 8.B.d), y Disposición transitoria quinta (f.j. 8.F).

$3^{\circ}$ Desestimar los recursos de inconstitucionalidad en todo lo demás.

\section{SENT. N ${ }^{\circ}$ 150/1991, DE 4 DE JULIO. PLENO. CUESTIONES DE INCONSTITUCIONALIDAD 1407/1989, 2187/1989, 187/1990 Y 188/1990 (ACUMULADAS). LUIS LOPEZ GUERRA.}

OBJETO: Promovidas por el Juzgado de Instrucción de Daroca (Zaragoza), sobre supuesta inconstitucionalidad de la agravante $n .{ }^{\circ} 15 \mathrm{del}$ art. 10 del Código Penal - reincidencia-, por entender que la citada norma es contraria a lo dispuesto en los arts. 1.1, 9.3, 10.1, 15 , 24.1 y 2 y 25.1 de la Constitución.

FALLO: Desestimar la cuestión planteada.

\section{B.O.E. DE 9 DE AGOSTO DE 1991. SUPLEMENTO DEL $N^{\circ} 190$}

\section{SENT. N $^{\circ}$ 155/1991, DE 10 DE JULIO. SALA SEGUNDA. RECURSO DE AMPARO No 183/1989. JOSE GABALDON LOPEZ.}

OBJETO: Interpuesto contra el Auto de 26 de septiembre de 1988 de la Sala de lo Contencioso-Administrativo de la Audiencia Territorial de Madrid. La solicitante de amparo formula dos quejas: de un lado, que siendo competente para conocer del asunto del que trae origen el presente recurso la Audiencia Territorial de Madrid, la Sala Cuarta de los Contencioso-Administrativo de este órgano judicial no declaró la nulidad, como se le solicitó, de las actuaciones previamente tramitadas ante la Audiencia Nacional, vulnerándose con ello el derecho al Juez ordinario predeterminado por la Ley; de otro lado, que tanto el recurso de súplica contra la providencia de la citada Sala de 18 de septiembre de 1986, como el de apelación contra la Sentencia dictada en el asunto el 3 de noviembre de 1986 fueron inadmitidos por supuesta extemporaneidad, al computar como hábil el día 15 de mayo de 1987, fiesta local en Madrid, error manifiesto que habría conculcado su derecho a la tutela judicial efectiva. 
FALLO: Desestimar el recurso de amparo, puesto que pese a que la Sala cometió error manifiesto al computar el plazo de recurso, sin embargo, el medio procesal inmediato para reparar jurisdiccionalmente el eventual error en la inadmisión pronunciada por el Juez o Tribunal es siempre el del recurso de queja ante el Tribunal Superior, de modo que la omisión del recurso de queja se convierte en motivo de desestimación del amparo.

\section{SENT. N 156/1991, DE 15 DE JULIO. SALA PRIMERA. RECURSO DE AMPARO ELECTORAL N ${ }^{\circ} 1442 / 1991$. FRANCISCO TOMAS Y VALIENTE.}

OBJETO: Promovido por el PSOE en las elecciones municipales de Sigüenza (Guadalajara), contra el Acuerdo de proclamación de concejales electos del citado Ayuntamiento por la Junta Electoral de Zona de Sigüenza, de 8 de junio de 1991, y la posterior Sentencia de la Sala de lo Contencioso-Administrativo del Tribunal Superior de Justicia de Castilla-La Mancha con sede en Albacete, de 27 de junio de 1991.

MATERIA: Supuesta vulneración del derecho fundamental de acceso en condiciones de igualdad a los cargos públicos (art. 23.2 CE): Papeletas rayadas declaradas nulas que desaparecen del expediente electoral.

- El demandante de amparo denuncia una lesión del derecho fundamental de acceso a los cargos públicos en condiciones de igualdad y con los requisitos que señalen las leyes (art. 23.2 CE), al entender que los votos que se tuvieron por nulos no lo eran y que su reclamación no ha podido ser convenientemente enjuiciada por haber desaparecido las papeletas del expediente electoral, irregularidad que, a su juicio, debe llevar a declarar la nulidad de la elección celebrada en la Mesa 1B.

- El TC entiende que el planteamiento impugnatorio de la candidatura actora no puede ser admitido pues adolece de un defecto de procedimiento (debió denunciarse ante la Mesa electoral correspondiente, al tiempo de realizarse el acta de la sesión, que no se acompañaban la totalidad de las papeletas declaradas nulas, defecto que por su claridad y sencillez pudo ser fácilmente advertido por la parte), se funda en unos datos acerca del expediente electoral que, una vez revisados, no resultan ser totalmente ciertos (sí está en el expediente electoral una de las tres papeletas reclamadas), $y$, finalmente, porque la irregularidad denunciada en sede constitucional, esto es, la infracción del art. 97.3 de la LOREG no es determinante del resultado electoral.

FALLO: Desestimar el recurso de amparo. 
JURISPRUDENCIA

\section{SENT. N' 157/1991, DE 15 DE JULIO. SALA PRIMERA. RECURSO DE AMPARO ELECTORAL N' $1470 / 1991$. FERNANDO GARCIA-MON Y GONZALEZ-REGUERAL.}

OBJETO: Interpuesto por la Agrupación Palmera de Independientes (API), contra Sentencia de la Sala de lo Contencioso-Administrativo del Tribunal de Justicia de Santa Cruz de Tenerife de 30 de junio de 1991.

MATERIAS: Vulneración del derecho a la tutela judicial efectiva: interpretación formalista del art. 108.2 LOREG.

- La demanda de amparo invoca como preceptos vulnerados el art. 24.1 CE por entender violado el derecho a la tutela judicial efectiva por no haber recibido respuesta del órgano jurisdiccional sobre el fondo de la cuestión ante él planteada; y el art. 23.2 de la Constitución por mantenerse un error en las elecciones al Cabildo Insular de la Palma contrario a dicho precepto.

- En este caso, la Sentencia recurrida entiende que no cabe pronunciarse sobre la cuestión de fondo suscitada, ya que la formación política recurrente no había satisfecho el requisito establecido por el art. 108.2 de la LOREG: haber hecho constar la incidencia denunciada bien en el acta de escrutinio de la Mesa electoral en cuyo seno se produjo el supuesto error material, bien en el acta de escrutinio general de la circunscripción. Por su parte, la demanda entiende que el art. 108.2 de la LOREG no puede limitar las facultades de revisión del órgano judicial, el cual, en consecuencia, debió entrar en el fondo de la cuestión planteada. En definitiva, se trata aquí de determinar si la interpretación y aplicación realizada del citado art. 108.2 de la LOREG es o no la más favorable a la plena eficacia de los derechos fundamentales de la actora, derechos que en el presente caso se concretan no sólo en el derecho a la tutela judicial efectiva, sino también al derecho de acceso a los cargos y funciones públicas del art. 23.2 CE.

- El TC entiende que no existiendo en el caso concreto falta de diligencia por parte de la candidatura actora y habiéndose agotado la vía administrativa previa, la Sala de lo Contencioso-Administrativo del Tribunal Superior de Justicia pudo y debió resolver sobre el fondo de la cuestión ante ella planteada, ya que no existía impedimento legal para ello, según la interpretación del art. 108.2 de la LOREG más favorable a la eficacia, tanto del derecho a obtener la tutela judicial efectiva (art. 24.1 CE), como del derecho material a acceder en condiciones de igualdad a las funciones 
y cargos públicos (art. $23.2 \mathrm{CE}$ ). En consecuencia, la respuesta dada por la Sentencia recurrida ha vulnerado el derecho a la tutela judicial efectiva, impidiendo un juicio sobre el fondo de la cuestión planteada ante la Sala de lo Contencioso-Administrativo mediante una interpretación rigorista y excesivamente formal del art. 108.2 de la LOREG.

Vulneración del derecho a acceder en condiciones de igualdad a las funciones y cargos públicos (art. 23.2 CE).

- El TC entiende que, en este caso, la somera referencia de la prueba practicada en las actuaciones que se hace por la Sentencia recurrida no es razonable, tanto porque no se realiza un análisis detenido de la misma, que, en cambio se contiene en las alegaciones del Fiscal y en el voto disidente, como por no ser correcta la conclusión a la que, en último término, llega la sentencia de mantener el error por no ser posible corregirlo, lesionándose así el derecho fundamental consagrado por el art. 23.2 CE.

- En consecuencia, procede rectificar el acuerdo de proclamación de candidatos electos al Cabildo de la Palma adoptado por la Junta Electoral Provincial de Santa Cruz de Tenerife el 10 de junio de 1991 , en lo que se refiere al número de votos obtenido por cada candidatura, declarando asimismo que la lista más votada, como consecuencia de dicha subsanación, ha sido la de la API. El error denunciado tiene una relevancia determinante en la designación del Presidente del Cabildo, cargo que, según el art. 201.5 de la LOREG, ha de recaer en el candidato primero de la lista más votada en la circunscripción insular.

FALLO: Otorgar el amparo solicitado por la API y, en consecuencia:

1. ${ }^{\circ}$ Declarar la nulidad de la Sentencia impugnada.

2. ${ }^{\circ}$ Declarar asimismo nulo el Acuerdo de la Junta Electoral Provincial de Santa Cruz de Tenerife de 10 de junio de 1991, por dicha Sentencia confirmado, en lo relativo a la proclamación de candidatos al Cabildo Insular de La Palma.

3. ${ }^{\circ}$ Restablecer a la API en la integridad de su derecho, para lo cual se remitirá testimonio de esta Sentencia a la Junta Electoral Provincial de Santa Cruz de Tenerife, para que proceda, en lo relativo a la proclamación de candidatos, al Cabildo Insular de La Palma, de conformidad con lo que se determina en los dos apartados finales del fundamento de Derecho 6 de esta Sentencia. 


\section{SENT. No 158/1991, DE 15 DE JULIO. SALA PRIMERA. RECURSO DE AMPARO ELECTORAL No $1471 / 1991$. CARLOS DE LA VEGA BENAYAS.}

OBJETO: Interpuesto por el PSOE contra la Sentencia de la Sala de lo Contencioso-Administrativo del Tribunal Superior de Justicia de Canarias de 25 de junio de 1991.

MATERIA: Supuesta vulneración del derecho de sufragio pasivo (art. 23.2).

- La Sentencia impugnada declaró nulo el acuerdo de la Junta Electoral de Zona de Icod de los Vinos de 3 de junio de 1991, por el que se había proclamado Concejal electo del Ayuntamiento de Los Silos (Santa Cruz de Tenerife) al candidato que figuraba en el puesto $\mathrm{n}^{\circ} 1$ de la lista electoral presentada por el PSOE en el indicado municipio. La razón de tal anulación consiste en la pena de «dos años de suspensión del cargo de Alcalde y de cualquier otro cargo público de la Administración Local que deba designarse mediante elección popular» que, como autor de un delito de denegación de auxilio del art. 371 del Código Penal, se le impuso en su día por la Audiencia Provincial al citado candidato y cuyo dies a quo de cumplimiento era el 21 de marzo de 1991.

- La representación del PSOE sostiene, principalmente, que se ha vulnerado el derecho de sufragio pasivo del candidato, toda vez que la pena de suspensión no conlleva, en los términos del art. 38 del Código Penal, la privación de aquel derecho.

- Pero el TC entiende que el candidato condenado a una pena de dos años de suspensión, que había empezado a cumplir el 21 de marzo de 1991, se hallaba, por tanto, incurso en una causa de inelegibilidad que le impedía figurar como candidato en las elecciones municipales para el Ayuntamiento de Los Silos. Naturalmente, las circunstancias de que la proclamación de candidatura del PSOE no hubiera sido impugnada jurisdiccionalmente y de que el candidato hubiera obtenido un resultado favorable dentro de aquella candidatura en los comicios posteriormente celebrados no convalidan o subsanan en absoluto la falta de capacidad electoral pasiva originaria de dicho candidato, que podía ser apreciada, como así fue, en la vía del recurso contencioso electoral contra la proclamación de electos, por lo que la Sentencia impugnada no vulnera el derecho fundamental aducido por el actor.

FALLO: Denegar el amparo solicitado. 


\section{SENT. N' 159/1991, DE 18 DE JULIO. PLENO. CUESTION DE INCONSTITUCIONALIDAD N' $267 / 1987$. FERNANDO GARCIA-MON Y GONZALEZ-REGUERAL.}

OBJETO: Formulada por el Pleno de la Audiencia Territorial de Oviedo sobre supuesta inconstitucionalidad del art. 39 de la Ley de la Junta General del Principado de Asturias 6/1984, de 5 de julio, «del Presidente y del Consejo de Gobierno del Principado de Asturias», que confiere fuero privilegiado a los miembros del Consejo de Gobierno del Principado. El citado art. 39 dispone que:

«1. La responsabilidad criminal de los Consejeros será exigible por los actos delictivos cometidos dentro del territorio de la Comunidad ante el Tribunal Superior de Justicia de Asturias. Fuera del territorio del Principado, la responsabilidad penal será exigible ante la Sala de lo Penal del Tribunal Supremo. 2. La responsabilidad civil de los Consejeros será exigible ante el Tribunal Superior de Justicia de Asturias».

MATERIAS: Fuero privilegiado de los miembros del Consejo de Gobierno del Principado de Asturias.

- El motivo fundamental de inconstitucionalidad aducido por la Audiencia Territorial de Oviedo se centra en la infracción de los principios de competencia y jerarquía normativa, al entender aquélla que una Ley autonómica no podría crear, como ha hecho la Ley asturiana, un fuero privilegiado para los miembros del Consejo de Gobierno. Ello se justifica por una doble argumentación:

1) Supone una modificación del Estatuto de Autonomía para Asturias sin seguir los trámites constitucionalmente establecidos para su modificación.

- El Estatuto de Autonomía para Asturias no incluyó el aforamiento procesal de los Consejeros, a diferencia de otros Estatutos, en los cuales se regula, con diversidad de matices, el aforamiento jurisdiccional de los componentes de los Ejecutivos autonómicos.

- El TC entiende que dada la falta de previsión estatutaria al respecto, no puede decirse que el art. 39.1 cuestionado haya modificado lo dispuesto en el Estatuto de Autonomía para Asturias sobre el status de los Consejeros.

2) Vulnera la competencia exclusiva del Estado para establecer las normas referentes a la Administración de Justicia, las leyes 
procesales, la organización de los Tribunales y la determinación de su competencia.

- Tanto el Consejo de Gobierno como la Junta General del Principado de Asturias defienden la competencia de la Ley autonómica por la referencia contenida en el art. 33.2 EAAs al Estatuto de los componentes del Consejo de Gobierno del Principado, expresión que entienden sería identificable con su Estatuto personal, lo que incluiría la regulación del fuero procesal de los mismos. Es decir entienden que el art. 33.2 contiene una habilitación al legislador autonómico para establecer el aforamiento antedicho.

- Pero el TC entiende que la delegación del art. 33.2 comprenderá en su regulación todas las materias relativas al Consejo de Gobierno que sean competencia de la Junta General del Principado, pero la delegación no se extiende a aquellas materias de competencia exclusiva del Estado conforme a la Constitución. El hecho de que en el Estatuto de Autonomía se hubiera podido regular directamente la materia, no permite entender que hubiera podido habilitar a la Ley autonómica para regular materias que son de la competencia exclusiva de la legislación del Estado.

- El precepto cuestionado realiza simultáneamente dos operaciones: una, sustraer a los citados Consejeros del régimen procesal común mediante la concesión de aforamiento; otra, atribuir a unos determinados órganos jurisdiccionales el conocimiento de un cierto tipo de causas penales, esto es, delimitar o enmarcar la competencia de los mismos. Así las cosas, y dado que el EAAs no ha establecido el fuero especial para los miembros del Consejo de Gobierno, ante esa omisión estatutaria, el art. impugnado no puede considerarse como expresión de la competencia autonómica de organización de sus instituciones de autogobierno. Este título competencial comprende la regulación del Estatuto de los Consejeros, pero con las limitaciones derivadas de las competencias constitucionalmente reservadas al Estado, que el legislador autonómico no puede invadir al efectuar aquella regulación. Dicho título competencial es el que el art. 149.1.6 CE atribuye con carácter exclusivo al Estado la materia de legislación procesal, en relación a lo previsto en los arts. 117.3 y $122.1 \mathrm{CE}$, en cuanto al establecimiento de la normativa orgánica de los Tribunales y a la determinación de su competencia; ello incluye el establecimiento del fuero jurisdiccional penal de los Consejeros asturianos, toda vez que el aforamiento constituye uno de los objetos de regulación de la legislación procesal. 
- La Ley Orgánica del Poder Judicial, en ejercicio de esa competencia exclusiva de la legislación del Estado, dispone en su art. 73.3 a) que a la Sala de lo Civil y Penal de los Tribunales Superiores de Justicia le corresponde, como Sala de lo Penal, el conocimiento de las causas penales que los Estatutos de Autonomía - y no otra Ley, y desde luego ninguna otra Ley autonómica- reservan a dichos Tribunales. Por tanto, resulta constitucionalmente inaceptable que una Ley autonómica como la impugnada, proceda por sí misma a establecer ex novo el fuero jurisdiccional penal de los miembros del Consejo de Gobierno de la $C A$,siendo así que se trata de una materia que pertenece a la exclusiva competencia estatal.

FALLO: Estimar la cuestión de inconstitucionalidad planteada, y declarar inconstitucional y, por tanto nulo, el art. 39 de la Ley asturiana impugnada.

\section{SENT. $N^{\circ} 160 / 1991$, DE 18 DE JULIO. PLENO. RECURSO DE AMPARO $\mathbf{N}^{\circ} 831 / 1988$. LUIS LOPEZ GUERRA.}

OBJETO: Interpuesto contra actuaciones materiales producidas por agentes públicos en virtud de las cuales, bien por vía de hecho o en ejecución de resoluciones administrativas no notificadas, se procedió a la demolición de los edificios del casco urbano de Riaño y, alternativamente, contra el Auto de la Sala Quinta del Tribunal Supremo, de 7 de abril de 1988, que desestima recurso de apelación contra Auto de la Sala de lo Contencioso-Administrativo de la Audiencia Territorial de Valladolid, de 27 de julio de 1987, que inadmitió un recurso contencioso-administrativo, planteado por el procedimiento de la Ley 62/1978. Al primero de los actos impugnados los actores le imputan la vulneración de los derechos fundamentales garantizados en la $\mathrm{CE}$ en los arts. 18.2 (inviolabilidad del domicilio) y 19 (libertad de residencia y circulación), la cual habría sido causada por la Administración y no remediada por los Tribunales. A la resolución judicial atacada le imputan una infracción procesal, consistente en haberles causado indefensión (art. 24), porque al inadmitir su recurso contencioso-administrativo les ha privado de la posibilidad de probar los hechos que constituyen la base de su recurso de amparo.

\section{MATERIAS:}

- La Sala de lo Contencioso-Administrativo de Valladolid se declaró incompetente por considerar que no había acto administrativo. 
JURISPRUDENCLA

Cuando los titulares de un cargo público - se dice en el fundamento jurídico $1 .^{\circ}$ del Auto de inadmisión-prescinden por completo del derecho en el ejercicio del mismo no hay verdadera actuación administrativa, sino una conducta ilegal generadora de la responsabilidad personal de sus autores. En consecuencia, la Sala de Valladolid declaró la inadmisión el recurso por incompetencia de la jurisdicción por tener como objeto la actuación material de demolición de la viviendas de Riaño que no constituye acto de la Administración Pública sujeto al Derecho Administrativo.

- El TC entiende que la Sala de Valladolid debió considerar, bien que las demoliciones estaban respaldadas por resoluciones administrativas (en concreto, por las órdenes de ejecución del Delegado del Gobierno, como señalaron los propios recurrentes), bien que existía una vía de hecho por exceso o extralimitación en las ejecuciones de las Sentencias que acordaron la expropiación. La Sala de Valladolid no entendió ni lo uno ni lo otro, sino que, haciendo una interpretación formalista y no razonable de las normas procesales denegó a los recurrentes la vía procesal oportunamente escogida por ellos, privando a los recurrentes de su derecho a la tutela judicial efectiva, pues al tratarse de un recurso de amparo de la Ley 62/1978, la declaración de falta de jurisdicción adquiere relevancia constitucional, que autoriza al TC a examinar su corrección jurídica.

- Pero la vulneración del derecho de los recurrentes a la tutela judicial efectiva no trae como consecuencia que, para remediar tal vulneración el TC deba remitir de nuevo el caso a la jurisdicción contenciosa para que ésta entre en el fondo del asunto, pues la retroacción de las actuaciones supondría una prolongación del procedimiento innecesaria y opuesta al mismo objeto del amparo constitucional. Corresponde, por tanto, al TC, y en la presente fase del procedimiento, resolver sobre el fondo de la cuestión planteada, reparando así la falta de tutela por parte de las instancias precedentes.

Supuesta vulneración del art. 18.2 CE que garantiza el derecho a la inviolabilidad del domicilio.

- Los recurrentes hacen radicar esa vulneración en que no hubo resolución judicial que autorizara el desalojo y derribo de sus domicilios en el municipio de Riaño.

- Pero el TC señala que en el presente supuesto nos encontramos ante unas actuaciones de desalojo y demolición de un conjunto amplio de edificaciones del municipio de Riaño, que se llevaron a cabo en cumplimiento de resoluciones judiciales firmes, 
confirmatorias por su parte de resoluciones administrativas expropiatorias de tierras, edificaciones y viviendas en el municipio citado. No estamos, por tanto, ante una actividad de la Administración de ejecución forzosa de sus propios actos amparada en el privilegio de la denominada autotutela administrativa, sino ante la ejecución de resoluciones judiciales firmes que autorizaron a la Administración a desalojar y derribar las viviendas expropiadas conforme a Derecho. Resulta así que hubo resolución judicial concerniente al desalojo de los hoy recurrentes, pues una resolución de los órganos jurisdiccionales relativa a la expropiación de viviendas implica el desalojo de los en ella habitantes, sin que sea necesaria una posterior resolución judicial para ejecutarla materialmente.

- En consecuencia, los desalojos y derribos se realizaron en ejecución de lo dispuesto en resoluciones judiciales que adquirieron firmeza, cuyo cumplimiento es obligado, y que versaban precisamente sobre el objeto del recurso, esto es, el desalojo y derribo de edificios, $y$, por tanto, no se ha vulnerado el derecho de los recurrentes a la inviolabilidad del domicilio.

Supuesta vulneración del art. 19 CE que garantiza el derecho a elegir libremente residencia.

- Tampoco se vulnera el derecho de los recurrentes a elegir libremente su residencia, puesto que una Sentencia acordando la expropiación y desalojo de edificaciones para la construcción de un pantano conlleva necesariamente el traslado de los hasta entonces residentes en ellas, e impide la continuidad de su permanencia, pero no impide que los que se vean desplazados elijan libremente su residencia, dentro de los límites que el ordenamiento imponga para defender los derechos de los demás, o los intereses generales, pues el derecho a la elección de residencia no es un derecho absoluto que habilite a ocupar cualquier vivienda o espacio, sino que, como el resto de los derechos, ha de ejercerse dentro del respeto a la Ley y a los derechos de los demás.

FALLO: Denegar el amparo solicitado.

\section{SENT. No 161/1991, DE 18 DE JULIO. SALA PRIMERA. RECURSO DE AMPARO No $1198 / 1988$. FRANCISCO TOMAS Y VALIENTE.}

OBJETO: Interpuesto contra las Sentencias de la Magistratura de Trabajo $n^{\circ} 11$ de Barcelona de 5 de junio de 1989 y del Tribunal Central 
de Trabajo de 22 de marzo de 1988 dictada en recurso de suplicación. El recurso tiene, en realidad, por objeto la Resolución de 15 de junio de 1984 del Departamento de Sanidad y Seguridad Social de la Generalidad de Cataluña.

MATERIA: Vulneración del principio de igualdad. Trato retributivo discriminatorio de Médicos en idéntica situación.

- En el presente recurso de amparo los actores -médicos del Centro de Asistencia Primaria de Canteres-denuncian la violación del art. $14 \mathrm{CE}$. La diferencia que supuestamente produce desigualdad inconstitucional y, por ende, discriminación, consiste en una determinada cantidad que, en concepto de complemento retributivo, asignó el Departamento de Sanidad y Seguridad Social de la Generalidad de Cataluña (Resolución de 15 de junio de 1984) a los médicos que prestan sus servicios en el Centro de Asistencia Primaria Ciudad Badía, y que no perciben los del Centro de Canteres. El objeto del recurso se circunscribe a determinar si el principio de igualdad exige la identidad de retribuciones, porque si es así habrá de concluirse que ante supuestos de hecho idénticos, cualquier diferencia de trato retributivo deberá estar objetivamente justificada, ya que de lo contrario será discriminatorio y, en consecuencia, lesivo del derecho a la igualdad, consagrado en el art. $14 \mathrm{CE}$.

- El TC entiende que una vez afirmada la identidad de servicios, funciones y cometidos que realizan los médicos de uno y otro centro, en el marco común de una experiencia de reforma dentro de la Sanidad Pública, hay que concluir que la Resolución del Departamento de Sanidad de Cataluña de 15 de junio de 1984, que prevé un complemento retributivo sólo para los médicos del Centro Ciudad Badía, con una dedicación de 36 horas semanales, es discriminatoria por establecer un trato retributivo distinto y sin justificación por la especificidad del régimen de prestación de servicios existente en el Centro Badía, no puede dejar de aplicarse a un centro que tiene idéntico régimen de servicios que aquél, compartiendo, como comparten ambos centros, la característica común de tener un régimen singular, que difiere sensiblemente del que se aplica con carácter general al colectivo médico de asistencia primaria de la Seguridad Social en Cataluña, que es lo que, según la propia Resolución de 15 de junio de 1984, justifica la asignación del complemento retributivo.

FALLO: Otorgar el amparo solicitado y, en su virtud:

1. ${ }^{\circ}$ Declarar nulas las Sentencias impugnadas. 
$2 .^{\circ}$ Reconocer el derecho de los actores a que se les retribuya su trabajo en condiciones de igualdad y, en consecuencia, su derecho a percibir el complemento retributivo establecido en la Resolución de 15 de junio de 1984 del Departamento de Sanidad y Seguridad Social de la Generalidad de Cataluña.

\section{SENT. $N^{\circ}$ 163/1991, DE 18 DE JULIO. SALA SEGUNDA. RECURSO DE AMPARO No 2943/1988. MIGUEL RODRIGUEZ-PIÑERO Y BRAVO-FERRER.}

OBJETO: Interpuesto contra la Sentencia de la Sala Quinta del Tribunal Supremo, de 4 de noviembre de 1988, por violación de los arts. 14 y $23.2 \mathrm{CE}$. El recurso tiene en realidad por objeto el Acuerdo del Pleno de la Diputación Provincial de Cuenca de 30 de noviembre de 1987.

MATERIA: Vulneración del art. 23.2 CE en cuanto se limita indebidamente el ejercicio del derecho del recurrente en tanto que miembro electivo de la Corporación Provincial.

- El Acuerdo del Pleno de la Diputación Provincial de Cuenca de 30 de noviembre de 1987 resolvió que el grupo mayoritario de la Corporación fijaría los criterios por los que se regiría la designación de representantes de la Corporación en la Caja de Ahorros de Cuenca y Ciudad Real, dando entrada a los grupos sociales mas representativos de la provincia, y acordando que «los miembros de la Corporación que serán nombrados representantes en la Asamblea General de la Caja de Ahorros de Cuenca y Ciudad Real serán en su totalidad componentes del grupo político provincial del partido socialista».

- Así, no cabe afirmar que la fijación de los criterios y la designación de las personas fuesen adoptadas en un debate abierto y libre, determinada por la relación de fuerzas políticas representadas en la Corporación, sino que resultaban claramente impuestas por esa previa decisión de remitirse a la voluntad del grupo mayoritario, con la explícita voluntad de excluir al grupo minoritario, y por ello al propio recurrente, del proceso de toma de decisión y de la posibilidad de elegir y ser elegido representante como miembro de la Corporación.

- El TC entiende que aquella vinculación apriorística que excluye sin fundamento objetivo y razonable toda posibilidad de elección de quienes no pertenecen al partido mayoritariamente representado, 
aunque ello pudiera producirse según las propias normas de funcionamiento del Pleno, y que impide debatir y proponer grupos sociales representativos y personas que los representen a los Diputados de la minoría, desde la perspectiva del art. $23.2 \mathrm{CE}$ constituye una diferencia injustificada e irrazonable, y una mediatización o exclusión ilegítima y arbitraria del ejercicio del cargo público representativo, que garantiza el art. $23.2 \mathrm{CE}$ y para el que fue elegido el recurrente, impedimento que de forma indirecta afecta también al derecho de sus electores a participar a través de la institución de la representación en los asuntos públicos.

- Ello debe determinar la Anulación del Acuerdo recurrido en su integridad para que el recurrente pueda ejercitar en el Pleno su derecho a participar en la designación de los miembros de la Asamblea general de la Caja de Ahorros de Cuenca y Ciudad Real, en representación de la Diputación Provincial de Cuenca como entidad cofundadora, con la correspondiente posibilidad de debate y propuesta, en lo que se refiere al establecimiento de los criterios por los que se regirá la designación, la determinación de los grupos o sectores sociales más representativos de la provincia a tener en cuenta, los criterios de elección de las personas que representen a dichos sectores y el derecho del recurrente a ser elector y elegible como miembro de la Corporación, dentro de los representantes de la misma en dicha Asamblea.

Sin embargo, no cabe hablar de discriminación por motivos ideológicos contraria al art. $14 C E$.

- El TC indica que no hay discriminación ideológica en el hecho de que al promover cargos públicos de naturaleza política se dé preferencia a los correligionarios, pues pertenece a la esencia de la democracia representativa la distinción entre mayoría y minoría y la ocupación por la primera de los puestos de dirección política.

FALLO: Estimar el amparo solicitado, y en su virtud:

$1 .^{\circ}$ Reconocer el derecho del recurrente a la igualdad en el ejercicio del cargo público representativo de Diputado provincial.

2..$^{\circ}$ Anular el acuerdo impugnado y la Sentencia que lo confirma, sin que esa declaración de nulidad suponga, sin embargo, la invalidación de los Acuerdos adoptados por la Asamblea general de Cajas de Ahorros, con participación de los designados según el acuerdo anulado por dicha Sentencia. 


\section{SENT. N 165/1991, DE 19 DE JULIO. SALA PRIMERA. RECURSO DE AMPARO ELECTORAL No 1496/1991. JESUS LEGUINA VILLA.}

OBJETO: Promovido por el PSOE contra la Sentencia de la Sala de los Contencioso-Administrativo del Tribunal Superior de Justicia de la Comunidad Valenciana, de 2 de julio de 1991, que estima recurso contencioso-electoral interpuesto por Izquierda Unida y revoca el Acuerdo de proclamación de concejales electos para el Ayuntamiento de Valencia realizado por la Junta Electoral de Zona. La candidatura solicitante de amparo reprocha a la citada Sentencia la lesión de varios derechos fundamentales.

MATERIAS: Supuesta vulneración del principio de igualdad en la aplicación judicial de la Ley (art. 14 CE).

- La candidatura demandante de amparo considera que la Sala sentenciadora mantuvo un diferente criterio sobre la validez del voto emitido en un sobre en el que se hubiesen introducido dos papeletas de un mismo partido.

- Pero en realidad no ha habido contradicción alguna entre las sentencias que en la demanda se comparan, sino sólo un mero error de transcripción, que produjo la confusión de la parte y que fue luego oportunamente corregido por la Sala en su Auto de aclaración.

Declaración como nulas de diversas papeletas por el hecho de aparecer escritas subrayadas, marcadas o tachadas.

- Entiende la demanda que la declaración como nulas de dichas papeletas ha lesionado la igualdad ante la Ley en fase de aplicación por la Administración electoral (art. $14 \mathrm{CE}$ ), como consecuencia del diferente trato dispensado a la candidatura recurrente, a estos efectos, respecto a otras candidaturas, y con ello se habrían violado también los derechos enunciados en el art. $23 \mathrm{CE}$, al no atenderse a la voluntad de los electores, y en el art. 24.1 CE en la medida en que el pronunciamiento judicial recaído estaría desprovisto de suficiente fundamentación jurídica.

- El TC entiende que la existencia constatada de marcas o tachaduras en las papeletas a las elecciones locales permite la aplicación razonada a las mismas por la Administración electoral y por los órganos de la jurisdicción contencioso-electoral de la nulidad prevista en el art. 96.2 de la LOREG, una vez atendidas y ponderadas las circunstancias de cada caso. El entendimiento de cuándo procede y 
cuándo no la aplicación de lo dispuesto en el art. 96.2 de la LOREG configura normalmente un juicio de estricta legalidad electoral que no puede ser revisado por el TC una vez comprobado que la interpretación seguida por el órgano judicial ordinario no es arbitraria, irrazonada o irrazonable. En consecuencia, no ha habido lesión del art. 23.2 CE por el hecho de que la Sala haya decidido tras la revisión de la minuciosa prueba documental practicada, declarar nulos diversos votos emitidos en papeletas señaladas con un aspa al lado de los candidatos, que contienen frases escritas, o que presentan interlineados y recuadros.

- Menos aún se advierte la vulneración del art. 14 CE por haber otorgado la Administración electoral un trato diferente a la aplicación de las normas que determinan la nulidad del voto. La demanda no ofrece términos válidos de comparación que hagan patente tal discriminación. Además, si a juicio de los demandantes se habían reconocido indebidamente como válidos determinados votos nulos de otras candidaturas por la Administración electoral, debieron impugnarse judicialmente tales acuerdos antes de formular la queja ante el TC.

- Tampoco cabe sostener que la Sentencia recurrida lesiona el art. 24.1 CE por carecer de fundamentación o de suficiente fundamentación. La Sala ha fundado su pronunciamiento en el art. 96 de la LOREG y, de acuerdo con el mismo, ha examinado los votos de cuya validez se discutía y los ha agrupado en los distintos supuestos legales, según el motivo determinante de su nulidad, razonando sucintamente su criterio en cada uno de ellos.

FALLO: Desestimar el presente recurso de amparo.

VOTOS PARTICULARES: Formulados por D. Francisco Tomás y Valiente, y por D. Vicente Gimeno Sendra.

\section{SENT. N$^{\circ}$ 166/1991, DE 19 DE JULIO. SALA PRIMERA. RECURSO DE AMPARO ELECTORAL N ${ }^{\circ} 1497 / 1991$. LUIS LOPEZ GUERRA.}

OBJETO: Interpuesto por el Partido Solidaridad Cívica de Alicante contra la Sentencia de la Sala de lo Contencioso-Administrativo del Tribunal Superior de Justicia de la Comunidad Valenciana, de 1 de julio de 1991.

MATERIA: Supuesta vulneración del art. 23.2 CE. Principio de conservación de los actos válidamente celebrados. 
- El problema suscitado en este proceso consiste en decidir si la Sentencia recurrida, al resolver que la nulidad decretada en una serie de mesas electorales de la circunscripción de Alicante no debía comportar una nueva convocatoria de elecciones en las mismas y al declarar la validez de la proclamación de concejales electos realizada por la Junta Electoral de Zona, ha infringido el derecho fundamental que el art. $23.2 \mathrm{CE}$ reconoce al candidato $n .^{\circ} 2$ de la lista presentada por el partido recurrente.

- El TC entiende que la decisión de la Sala, estimando que los votos de destino desconocido no resultan determinantes y, en consecuencia, no acordando la convocatoria de nuevas elecciones en las mesas afectadas, resulta plenamente acorde con la doctrina del TC sobre el principio de conservación de los actos válidamente celebrados, sobre todo cuando se trata de conservar el ejercicio de los derechos fundamentales de los electorales (art. 23.1 CE) en todos aquellos casos en que los sufragios no se vean afectados por las irregularidades apreciadas. Ciertamente, el sistema de ponderación utilizado por la Sala, y consistente en aplicar a los votos inciertos el porcentaje de sufragios obtenidos por el partido recurrente en toda la circunscripción, no es el único de los posibles, pues cabría también, por ejemplo, tomar como cifra porcentual la de los sufragios conseguidos en las papeletas válidas de las mesas cuestionadas. Sin embargo, el sistema empleado por el Tribunal Superior de Justicia de la Comunidad Valenciana es perfectamente admisible, por lo que no cabe apreciar que en su aplicación se hayan vulnerado los derechos alegados por el recurrente.

FALLO: Desestimar el recurso interpuesto.

\section{SENT. No 167/1991, DE 19 DE JULIO. SALA PRIMERA. RECURSO DE AMPARO ELECTORAL N' 1503/1991. FRANCISCO TOMAS Y VALIENTE.}

OBJETO: Interpuesto por la Coalición Electoral Izquierda Unida de Murcia, contra la Sentencia dictada el 2 de julio de 1991 por la Sala de lo Contencioso-Administrativo del Tribunal Superior de Justicia de la Región de Murcia, que confirma los actos administrativos entonces impugnados por la actora y dictados por la Junta Electoral de Zona de Mula (Acuerdos de 31 de mayo y de 8 de junio de 1991, de estimación parcial, el primero, de la reclamación formulada por el PSOE; y de proclamación, el segundo, de candidatos electos), habiendo recaído, asimismo, Acuerdo de la Junta Electoral Central, de 6 de junio de 1991, desestimatorio del recurso de la actora contra la primera de aquella resoluciones. 
JURISPRUDENCIA

MATERIA: Nulidad de los votos emitidos en papeletas correspondientes a candidaturas presentadas en otras circunscripciones.

- La tesis de la recurrente es la de que los votos emitidos en papeletas correspondientes a candidaturas presentadas en otras circunscripciones nunca debieron ser computadas en favor de la candidatura que el mismo partido político (el PSOE) presentó en el municipio de Molina de Segura, y ello porque tales papeletas expresarían un sufragio en favor de quienes no eran candidatos proclamados en esta última circunscripción municipal.

- Pero no fue éste el criterio de las Juntas Electorales Central y de Zona que aquí se pronunciaron y tampoco el del Tribunal de Murcia, órganos que dieron por buenas - por válidas en Molina de Segura - aquellas papeletas, al estimar inequívoca la intención de quienes "por error" las depositaron en las urnas y al considerar, junto a ello, que la citada irregularidad no tenía encaje en los supuestos de nulidad del voto del art. 96 de la LOREG.

- Sin embargo el TC entiende que aunque la elección se produzca hoy en España, en los comicios municipales y en otros, entre listas "cerradas" y "bloqueadas", la elección es de personas (de candidatos presentados por partidos políticos, coaliciones electorales o agrupaciones de electores, debidamente proclamados como tales) y cualquier otra concepción pugna con la Constitución y con la misma dignidad de posición de electores y elegibles, porque ni los primeros prestan, al votar, una adhesión incondicional a determinadas siglas partidarias ni los segundos pierden su individualidad al recabar el voto desde listas de partido. Por tanto, aun cuando se entendiera que las papeletas aquí controvertidas fueron depositadas por error, la conclusión no debiera haber sido la de su convalidación pues la democracia participativa que la Constitución establece no queda realizada con un sufragio irreflexivo o de otro modo desatento a la identidad de las personas que figuran como candidatos en las listas electorales, y el ordenamiento no puede reconocer eficacia a tales actitudes.

- Esta es también la concepción de la elección que se expresa en la LOREG, cuya falta de referencia expresa en el art. 96 a una irregularidad como la aquí examinada no debe ser obstáculo para privar de toda eficacia, en el acto de escrutinio, a papeletas de voto en las que no figuran candidatos proclamados en la circunscripción. La enumeración de supuestos de nulidad que contiene aquel precepto no es, desde luego, ad exemplum, sino tasada, pero implícito o sobreentendido en todos ellos, y también en el resto del articulado aplicable, 
está el que en las papeletas de voto deben figurar, como es obvio, candidatos proclamados en la circunscripción y que cuando así no sea el sufragio - en realidad inexistente- queda viciado total y absolutamente.

- Por tanto, la interpretación disconforme a la Constitución que permitió la convalidación de los votos en cuestión resulta lesiva del derecho de los demás candidatos (y de los que figuraron, por tanto, en la lista presentado por IU) a acceder, en condiciones de igualdad, al cargo de Concejal (art. 23.2 CE). Rompe esa igualdad la atribución a una de las listas en liza de votos que sus candidatos no recibieron; que nadie, en rigor, recibió.

FALLO: Otorgar el amparo solicitado y, en consecuencia:

1. ${ }^{\circ}$ Declarar la nulidad de los Acuerdos de la Junta Electoral de Zona de Mula y de la Junta Electoral Central, en la parte de tales resoluciones en la que se reconoce validez y eficacia a siete votos en su día considerados nulos por las Mesas electorales de Molina de Segura al figurar en papeletas de candidaturas presentadas por el PSOE en otras circunscripciones.

$2{ }^{\circ}$ Declarar la nulidad de la Sentencia impugnada, debiéndose dictar nueva Sentencia por dicho Tribunal en el marco de lo dispuesto en el art. 113.2 de la LOREG.

3. ${ }^{\circ}$ Reconocer el derecho de los candidatos de IU en el municipio de Molina de Segura a que no se atribuya validez, en el acto de escrutinio, a las papeletas en las que no figuren personas que no fueron proclamadas candidatos en las elecciones municipales de las que trae causa este recurso según requiere el art. $23.2 \mathrm{CE}$.

\section{SENT. No 168/1991, DE 19 DE JULIO. SALA PRIMERA. RECURSO DE AMPARO ELECTORAL $\mathbf{N}^{\circ} 1505 / 1991$. FERNANDO GARCIA-MON Y GONZALEZ-REGUERAL.}

OBJETO: Promovido por el CDS contra la Sentencia de la Sala de lo Contencioso-Administrativo del Tribunal Superior de Justicia de Canarias, de 2 de julio de 1991, que estima parcialmente el recurso contencioso-electoral interpuesto por el citado partido respecto del Acuerdo de proclamación de concejales electos para el Ayuntamiento de Las Palmas de Gran Canaria. Supuesta vulneración de los arts. 23.2 y $24.1 \mathrm{CE}$. 
JURISPRUDENCIA

MATERIAS: Necesidad de agotar la vía administrativa electoral previa.

- Considera el demandante de amparo que la Sentencia impugnada vulneró los derechos fundamentales de los miembros de su candidatura al Ayuntamiento de Las Palmas de Gran Canaria, derechos comprendidos en los arts. 23.2 y $24.1 \mathrm{CE}$, al haberse negado la Sala a la revisión de las irregularidades denunciadas en dos de las nueve Mesas electorales reclamadas, en virtud de no haber agotado convenientemente la vía administrativa electoral.

El TC señala que la interposición del recurso contencioso-electoral requiere el conveniente agotamiento de la vía administrativa previa, constituida por las reclamaciones ante las Juntas Electorales de Zona y Central, entre otras razones, para apurar el complejo sistema de garantías que la Ley prevé. Es, por lo demás, patente, que la jurisdicción del orden contencioso-administrativo, en la que se inserta la competencia para conocer del recurso contencioso-electoral, viene diseñada en nuestro ordenamiento en relación con disposiciones y actos de la Administración que no sean susceptibles de ulterior recurso en vía administrativa.

- Una cosa es que quepa modular las exigencias del principio de preclusividad en materia de procedimiento electoral (art. 108.2 de la LOREG), evitando rigorismos excesivos que impidan la plena revisión jurisdiccional, mediante la exigencia tan sólo de la diligencia debida en cada supuesto a la hora de advertir el momento en que los actores pudieron denunciar la irregularidad, y otra bien distinta es que las candidaturas que reclamen la presencia de irregularidades en el procedimiento electoral puedan disponer a su antojo del agotamiento o no de la vía administrativa previa a la contencioso-electoral.

- Constan en el expediente electoral sendos escritos del recurrente en los que fundamenta el recurso contencioso-electoral contra la proclamación de electos en la presencia de errores materiales de transcripción de los resultados y de confección de las Actas de sesión en 9 Mesas, entre las que se encuentran las Mesas ahora controvertidas y sin hacer distingos respecto de las otras. Habida cuenta de que las irregularidades denunciadas eran las mismas, sustancialmente, para todas la Mesas, es razonable exigir como diligencia debida que se denunciaran en la vía administrativa los defectos advertidos en estas dos Mesas al igual que se hizo con el resto.

Inadmisión por la Sala de determinados medios de prueba.

- También se funda la demanda en que la denegación por la Sala de algunas pruebas solicitadas por el recurrente - testifical y pericial, 
puesto que la documental fue admitida-, le causaron la indefensión prohibida por el art. 24.1 CE.

- Como ha señalado reiteradamente el TC, la pertinencia de las pruebas y su valoración y apreciación, corresponde exclusivamente en virtud de los dispuesto en el art. 117.3 CE a los órganos judiciales, y sólo procederá su revisión en sede constitucional cuando no sean razonables los fundamentos de su denegación, o se demuestre por el recurrente que eran decisivas para la resolución del pleito, lo que no ocurre en el presente caso.

FALLO: Desestimar el recurso de amparo.

\section{SENT. N$^{\circ}$ 269/1991, DE 19 DE JULIO. SALA PRIMERA. RECURSO DE AMPARO ELECTORAL N ${ }^{\circ} 1507 / 1991$. CARLOS DE LA VEGA BENAYAS.}

OBJETO: Formulado por el CDS contra la Sentencia de la Sala de lo Contencioso-Administrativo del Tribunal Superior de Justicia de Castilla y León de 28 de junio de 1991. Este recurso de amparo es de carácter mixto, ya que las imputaciones contenidas en el escrito de demanda sobre la pretendida lesión de los arts. 14 y $23.1 \mathrm{CE}$ han de entenderse dirigidas más bien a la Junta Electoral de Zona de Lerma, cuyo acuerdo de proclamación de concejales electos en el municipio de Torresandino (Burgos), confirmado luego en el proceso contencioso electoral, sería el acto originariamente causante de aquella lesión; de otra parte, el recurrente atribuye a la Sentencia del Tribunal Superior de Justicia de Castilla y León la vulneración de su derecho fundamental a la tutela judicial efectiva (art. 24.1 CE).

\section{MATERIAS: Supuesta vulneración del art. 24.1 CE}

- Esta imputación se basa por el actor en que el órgano judicial no entró a analizar el motivo impugnatorio relativo a la consideración como nulo del voto de la electora que había depositado el sobre con la papeleta propia de las elecciones municipales en la urna destinada a las autonómicas. Ello porque, al decir de la Sentencia, dicho motivo no había sido objeto de la reclamación prevista en el art. 108.2 LOREG, reclamación que "constituye el presupuesto de la acción jurisdiccional y es la medida del contenido de ésta».

- El CDS formuló reclamación ante la Junta Electoral de Zona de Lerma al amparo del citado art. 108 LOREG, pero sin aducir el motivo impugnatorio que nos ocupa. De ahí que la Resolución de 
JURISPRUDENCLA

31 de mayo de 1991, de la indicada Junta, que desestimó la reclamación presentada, no se hubiera pronunciado acerca de tal motivo. Este aparece por primera vez en el recurso que contra la Resolución de la Junta de Lerma se dedujo ante la Junta Electoral Central, la cual en su acuerdo desestimatorio del siguiente 5 de junio, entendió que, dados los términos del inciso final del art. 108.2 LOREG, no cabía entrar a pronunciarse acerca de un extremo no planteado anteriormente, con independencia de que, visto el resultado que consta en el acta de escrutinio general, un solo voto no alteraría dicho resultado.

- Así, la Sala sentenciadora no ocasionó al recurrente lesión alguna de su derecho a la tutela judicial efectiva en el extremo que analizamos, pues la utilización de las reclamaciones y protestas ante la Junta Electoral competente en relación con las incidencias recogidas en las actas de sesión de las Mesas electorales (art. 108.2 LOREG) no puede considerarse como potestativa para los representantes y apoderados de las candidaturas, de modo que a éstos les cupiera acudir per saltum al contencioso electoral. Resultando fundado en Derecho el criterio de la Sala, es obvio que el motivo atinente a la consideración como nulo del voto introducido en una urna distinta a la que le correspondía no puede ser ahora examinado, toda vez que en este extremo el partido actor no ha agotado la vía procedente.

\section{Supuesta vulneración del art. 23.1 CE}

- Se alega la infracción del art. 23.1 CE como consecuencia del impedimento puesto a tres electoras que quisieron ejercitar el voto personalmente, denegándoselo so pretexto de haberlo solicitado por correo.

- El TC entiende que este derecho no se ha visto infringido en este caso, pues la interpretación que la Sentencia recurrida efectúa del art. 73.1 LOREG no es arbitraria. Este precepto, al disponer que por la Delegación Provincial de la Oficina del Censo Electoral se realizará en el censo la anotación correspondiente (la de la solicitud de voto por correo), a fin de que el día de las elecciones no se realice el voto personalmente, tiene un sentido inequívoco: el de prohibir el voto de tales solicitudes ante la Mesa electoral. La prohibición no cede porque el solicitante no haya recibido con la suficiente antelación la documentación interesada o cuando, próximo a cerrarse el colegio electoral el día de la votación, se constate que el Servicio de Correos no ha entregado a la Mesa la correspondencia con el sufragio del referido solicitante, según pretende el actor. 
Supuesta vulneración del art. $14 C E$.

- Se aduce por el recurrente que el Presidente de la Mesa de Torresandino, no obstante denegar a otros electores su pretensión de votar directamente al constar su condición de solicitantes del voto por correo, él mismo emitió el sufragio a pesar de hallarse en tal situación, lo que resulta atentatorio al principio de igualdad.

- Pero como señala reiteradamente el TC, no cabe pretender la igualdad en la ilegalidad -e ilegal fue la acción del Presidente citado- y el voto así emitido fue considerado nulo por la Sentencia impugnada, de modo que el motivo esgrimido adolece de inconsistencia.

FALLO: Denegar el amparo solicitado.

\section{SENT. N$^{\circ}$ 170/1991, DE 19 DE JULIO. SALA PRIMERA. RECURSO DE AMPARO ELECTORAL No 1515/1991. JESUS LEGUINA VILLA.}

OBJETO: Interpuesto por la Coalición Electoral Barcelona Verda, contra la Sentencia del Tribunal Superior de Justicia de Catalunya de 1 de julio de 1991, recaída en recurso contencioso-electoral.

MATERIAS: Proclamación supuestamente indebida de otra candidatura:

a) Supuesta vulneración de la tutela judicial efectiva.

- La coalición recurrente dice que se le ha denegado la tutela judicial efectiva al no haber entrado la Sala en el fondo de la reclamación relativa a la proclamación supuestamente indebida de otra candidatura.

- Pero el TC entiende que la inadmisión del recurso contencioso-electoral en el supuesto de autos es completamente razonable. La Ley Electoral contempla dos posibilidades de revisión judicial en el curso del proceso electoral: una relativa a la proclamación de candidatos (art. 49 LOREG) y otra relativa a la proclamación de electos (art. 108 y ss. LOREG). Es evidente que en lo que concierne a las irregularidades de naturaleza subsanable que presenten las candidaturas, quien quiera impugnar su proclamación ha de utilizar el procedimiento especifico que la Ley Electoral ha dispuesto para ello. La inactividad en dicho momento supone un aquietamiento respecto al acto de proclamación de candidaturas, congruente en un procedimiento como el electoral que ha de 
contar con plazos fugaces, perentorios y preclusivos y en el que tanto las partes como la Administración electoral han de actuar con extrema diligencia. Aunque la coalición recurrente afirma haber efectuado diversas denuncias en relación con las irregularidades en que incurría, en su opinión, otra candidatura, lo cierto es que no hizo uso del recurso judicial contemplado en el art. 49 LOREG. Por tanto, la calificación de la queja como extemporánea en un recurso posterior concebido para impugnar la proclamación de candidatos ya electos (y no de candidaturas) es totalmente irreprochable.

b) Supuesta vulneración del principio de igualdad.

- La alegación relativa a la vulneración del principio de igualdad es asimismo infundada. De un lado, porque no puede la coalición actora afirmar tal vulneracion por comparación con resoluciones de distinta Junta Electoral; de otro, porque también en este caso se trata de una queja respecto a la cual no se ha agotado la vía judicial previa, según requiere el art. 43 LOTC, y que no es otra que el recurso del art. 49 de la LOREG.

FALLO: Desestimar el recurso de amparo. 
